\title{
Noninvasive myocardial strain measurement by speckle tracking echocardiography in everyday practice
}

\section{Diana Rudan*, Ivana Jurin, \\ Sandra Jakšić Jurinjak, Josip Vincelj}

University Hospital Dubrava, Zagreb, Croatia
RECEIVED:

March 11, 2017

ACCEPTED:

April 6, 2017

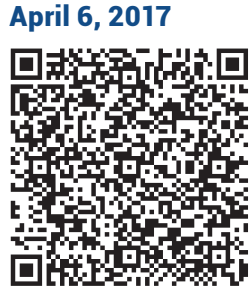

KEYWORDS: echocardiography, strain, speckle tracking.

CITATION: Cardiol Croat. 2017;12(4):121. | https://doi.org/10.15836/ccar2017.121

*ADDRESS FOR CORRESPONDENCE: Diana Rudan, Klinička bolnica Dubrava, Avenija Gojka Šuška 6, HR-10000 Zagreb, Croatia. / Phone: +385-91-333-7771 / E-mail: drudan3@yahoo.com

ORCID: Diana Rudan, http://orcid.org/0000-0001-9473-2517 • Ivana Jurin, http://orcid.org/ 0000-0002- 2637-9691 Sandra Jakšić Jurinjak, http://orcid.org/0000-0002-7349-6137• Josip Vincelj, http://orcid.org/0000-0003-0064-9128

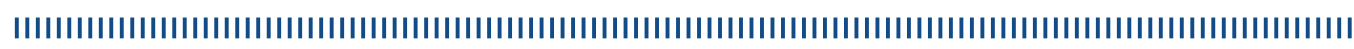
Non-invasive assessment of regional myocardial function is important for diagnosing of myocardial disease, assessing therapeutic interventions, and predicting clinical outcomes. Although there are other non-invasive techniques for assessment of myocardial function, such as magnetic resonance imaging and computed tomography, echocardiography remains the tool of choice in widespread clinical use because of the ease of its usage. Echocardiographic strain imaging, also known as deformation imaging, is a technological advancement that has been developed to objectively quantify regional myocardial function ${ }^{1,2}$. Currently, most echo-laboratories use speckle tracking computer processing to assess myocardial function in many diseases. In this paper, we will show the role that speckle tracking plays in our daily clinical routine. regional myocardial function. Circulation. 2000 Sep 5;102(10):1158-64. https://doi.org/10.1161/01.CIR.102.10.1158

2. Dandel M, Hetzer R. Echocardiographic strain and strain rate imaging- clinical application. Int J Cardiol. 2009 Feb 6;132(1):11-24. https://doi.org/10.1016/j.ijcard.2008.06.091 